\title{
Don't stress: a case report of regional anesthesia as the primary anesthetic for gynecologic surgery in a patient with mitochondrial myopathy and possible malignant hyperthermia susceptibility
}

\author{
Marci B. Pepper (D), Catherine Njathi-Ori and Michelle Ochs Kinney
}

\begin{abstract}
Background: We aim to describe the evaluation and management of a patient with the uncommon combination of both mitochondrial myopathy and possible malignant hyperthermia susceptibility as an important source of information and as a valuable example of the role of regional anesthesia for patients with these diagnoses.

Case presentation: A 24 year old woman with a history of possible mitochondrial myopathy and possible malignant hyperthermia susceptibility presented for gynecologic surgery. Surgery was well tolerated with combined spinal epidural anesthesia as well as sedation with midazolam, ketamine, and fentanyl.

Conclusions: Anesthetic management of patients with mitochondrial myopathy is challenging, made even more so with concurrent malignant hyperthermia susceptibility. This case adds an example to the literature of employing regional anesthesia as a safe approach to this complex care.
\end{abstract}

Keywords: Regional anesthesia, Combined spinal epidural, Mitochondrial myopathy, Malignant hyperthermia

\section{Background}

Anesthetic management of patients with mitochondrial myopathy $(\mathrm{MM})$ is challenging: the incidence is low, the phenotype and comorbidities are heterogeneous, every organ system may be involved, and evidence based guidelines are lacking [1]. Recent review articles provide helpful discussion of principles of perioperative management of patients with MM [1-3]. A thorough preoperative evaluation to identify and qualify severity of systemic involvement is required. Care must be taken to avoid tipping the balance of energy supply and demand, including checking baseline $\mathrm{pH}$ and lactate levels followed by perioperative monitoring $[1,3]$. Since these

\footnotetext{
* Correspondence: Pepper.Marci@mayo.edu

Prior Presentation: This work was presented at the 2019 Regional

Anesthesiology and Acute Pain Medicine Meeting of the American Society of Regional Anesthesia and Pain Medicine in Las Vegas, Nevada, April 11 to April 13, 2019.

Mayo Clinic Department of Anesthesiology and Perioperative Medicine, 200 First Street SW, Rochester, MN 55905, USA
}

patients may have defects in energy production and use, they should have minimization of fasting times and perioperative monitored glucose supplementation to avoid both hypo- and hyperglycemia [1-3]. Metabolic demands should be minimized, including avoidance of stress, pain, nausea and vomiting, and hypoxemia, and maintenance of normothermia [1-3]. Preparations ought to be made for possible increased sensitivity to anesthetic and analgesic agents and neuromuscular blockade [1-3]. Although the safety of propofol use in patients with MM is unsettled, and a single bolus dose is likely tolerated, avoidance of propofol-based total intravenous anesthetic (TIVA) is recommended as it may lead to propofol infusion syndrome [1-3]. Patients with MM are unlikely to truly have malignant hyperthermia $(\mathrm{MH})$; however, succinylcholine administration in myopathic patients may cause hyperkalemia or anesthesia induced rhabdomyolysis, so it should be avoided [1]. Regional anesthesia should be used whenever possible.

(c) The Author(s). 2019 Open Access This article is distributed under the terms of the Creative Commons Attribution 4.0 International License (http://creativecommons.org/licenses/by/4.0/), which permits unrestricted use, distribution, and 
While these principles are helpful and these review articles belong in the anesthesiologist's armamentarium, in the setting of minimal evidence-based guidelines, case reports continue to be valuable in guiding and providing examples of management of these complex patients with sometimes unclear diagnoses. Thus, we present a case of a patient with both $\mathrm{MM}$ and $\mathrm{MH}$ susceptibility managed with regional anesthesia and sedation for a gynecologic surgery. Written authorization from the patient was provided for submission of a case report.

\section{Case presentation}

A 24 year-old, 95 kilogram (Kg), 165 centimeter (cm) woman was scheduled for a diagnostic laparoscopy for an indeterminate pelvic mass. Historical workup more than 5 years prior for congenital hypotonia, delayed acquisition of motor skills, persistent discoordination, and chronic fatigue included a muscle biopsy with pathologic examination and oxidative phosphorylation enzymology as well as a mitochondrial deoxyribonucleic acid (DNA) and multi-gene panel for cellular energetic defects including 656 genes. Skeletal muscle oxidative phosphorylation enzymology was equivocal for a possible complex 1 defect and decreased enzymatic activity of complex 1 was observed. Although no associated mitochondrial DNA defect was identified, she acquired a diagnosis of possible MM. Gene sequencing revealed a variant of uncertain significance, reported with conflicting predictions of "possibly damaging" and "tolerated," in the ryanodine receptor 1 (RYR1) gene (Position Chromosome 19: 38955314, Exon 23, Variant c.[2822C > T]), suggestive of possible $\mathrm{MH}$ susceptibility. There was no family history of $\mathrm{MH}$. Additional studies included normal electromyography, brain magnetic resonance imaging, electrocardiogram, and transthoracic echo. Her past medical history was otherwise notable for fibromyalgia/chronic musculoskeletal pain, possible spondyloarthropathy, endometriosis, adnexal cyst, and ectopic pregnancy. She had undergone prior surgical procedures with neuraxial or peripheral nerve blockade. She was warned by medical providers elsewhere to avoid propofol, lactated Ringer's solution, and succinylcholine.

Given this history, we favored regional anesthesia and the surgical service agreed to an open rather than the originally scheduled laparoscopic procedure. She was pre-medicated with 1 gram $(\mathrm{g})$ oral acetaminophen and intravenous (IV) fentanyl 50 micrograms (mcg) and midazolam 3 milligrams (mg). A combined spinal epidural procedure was performed with the patient sitting upright and with midline approach at lumbar interspace 3-4 with an 18 gauge Tuohy needle, 27 gauge Whitacre needle, and 20 gauge epidural catheter. Loss of resistance with preservative-free normal saline was obtained at 6 $\mathrm{cm}$. Intrathecal injection of 2 milliliters $(\mathrm{mL}) \quad 0.75 \%$ bupivacaine with $8.25 \%$ dextrose, 15 mcg fentanyl, and $200 \mathrm{mcg}$ epinephrine was performed. The epidural catheter threaded easily and a test dose of $3 \mathrm{~mL}$ of $1.5 \%$ lidocaine with $5 \mathrm{mcg} / \mathrm{mL}$ epinephrine was negative for intrathecal or intravascular catheter location. Approximately 30 min later, the patient had a dermatomal level around thoracic $(\mathrm{T})$ spinal nerve $\mathrm{T} 8$, so the catheter was bolused with $10 \mathrm{~mL}$ of $2 \%$ lidocaine. After confirming T6 dermatomal level, incision was made. Anesthesia was maintained with divided doses of $10 \mathrm{~mL} 0.5 \%$ bupivacaine with $5 \mathrm{mcg} / \mathrm{mL}$ epinephrine and $10 \mathrm{~mL} 2 \%$ lidocaine. For sedation, in addition to previously mentioned pre-medications, she received IV divided doses of $30 \mathrm{mg}$ ketamine, $9 \mathrm{mg}$ midazolam, and $550 \mathrm{mcg}$ fentanyl. For antiemetics she received $0.625 \mathrm{mg}$ droperidol IV, $4 \mathrm{mg}$ dexamethasone IV, and $4 \mathrm{mg}$ ondansetron IV. She was maintained on a 5\% dextrose and normal saline IV infusion at $100 \mathrm{~mL} /$ hour with intraoperative point-of-care glucose monitoring. Baseline and perioperative lactates were not monitored, although in retrospect we would include this laboratory evaluation. Skin temperature was monitored and normothermia was maintained with a forced air warmer. Surgical time was $4 \mathrm{~h}$ and included Pfannenstiel incision, lysis of adhesions, and left ovarian cystectomy. At the conclusion of the case the surgeons infiltrated the wound with a solution of $20 \mathrm{~mL} \mathrm{1.3 \%} \mathrm{lipo-}$ somal bupivacaine in $100 \mathrm{~mL}$ normal saline and the epidural catheter was removed. The procedure was well tolerated without complications. The patient was discharged home on postoperative day three.

\section{Discussion \& Conclusions}

When a patient presents for surgery with a history suggestive of MM, the diagnostic features of this spectrum of disorders make anesthetic evaluation, planning, and decisions difficult. Although there are some well characterized mitochondrial myopathic syndromes, some genetic mutations have incredibly variable clinical presentations and some similar clinical presentations can be caused by different genetic mutations [1]. Moreover, although massive parallel or next-generation genetic sequencing methodologies have emerged as a new gold-standard for accurate diagnosis of mitochondrial DNA disorders [3], their increased availability and use can reveal genetic mutations of uncertain clinical significance, particularly to the anesthesiologist making assessments in a brief perioperative window. History of muscle biopsy with pathology and biochemical testing can add diagnostic clarity, but these tests might have limited sensitivity and specificity and add insufficient information to aid in formulation of an anesthetic plan [3]. The increased availability of gene sequencing has implications for evaluating patients with possible MH susceptibility, as well. Patients may present with a list of results, 
frequently including variants of uncertain significance, without corresponding interpretation or recommendations from medical geneticists or genetic counselors. Our approach is to apply $\mathrm{MH}$ precautions and nontriggering anesthetics to these patients unless their results have been clearly interpreted by a qualified provider as benign. Our patient had laboratory variations suggestive of possible MM and an indeterminate RYR1 defect suggestive of possible $\mathrm{MH}$ susceptibility. We aimed to presumptively optimize her care.

Even in the setting of diagnostic clarity, anesthetic management of patients with MM can be challenging because of the wide and variable degree of systemic involvement. Elucidating quality and severity of individual patient signs and symptoms preoperatively, which can include cardiomyopathy, arrhythmias, respiratory or skeletal muscle weakness, dysphagia, risk for rhabdomyolysis, seizures, neuropathy, and kidney and liver dysfunction, among other relevant considerations for the anesthesiologist, is paramount [1]. Our patient had primarily musculoskeletal complaints without any objective evidence of widespread systemic derangements, posing fewer limitations on our anesthetic plan than might be the case with other patients with MM.

Although patients with MM ought not to get succinylcholine due to risk of hyperkalemia or anesthesia induced rhabdomyolysis, they are not considered to be at higher risk than average for developing true MH. However, the two diseases can coexist, and this very uncommon coexistence was a concern in our patient with an indeterminate RYR1 mutation. These concurrent laboratory variations added a layer of complexity to her care and pushed us strongly in favor of a primarily regional anesthetic. In addition to following the aforementioned perioperative recommendations regarding the balancing of metabolic supply and demand and precautions about sensitivity to anesthetic and analgesic agents, we chose to avoid $\mathrm{MH}$ triggering agents. Although controversial, avoidance of propofol in MM is recommended because of increased risk of propofol infusion syndrome [1]. Essentially all anesthetic agents depress mitochondrial function and many are potent inhibitors of complex 1 [2]; however, there are reports describing successful general anesthetics for patients with both MM and MH with induction with ketamine, methohexital, and fentanyl followed by maintenance with methohexital, dexmedetomidine, and sufentanil infusions [4], induction with midazolam, fentanyl, and ketamine followed by maintenance with ketamine infusion and inhaled nitrous oxide [5], and induction with fentanyl and etomidate followed by maintenance with remifentanil and dexmedetomidine infusions and inhaled nitrous oxide [5]. In summary, there is no consensus regarding an ideal anesthetic for these patients, in part because patients with these disorders are highly variable, but a number of parenteral agents and nitrous oxide have been used judiciously and safely [2]. Nevertheless, regional anesthesia is preferable when possible, so we proceeded with neuraxial technique. We considered dexmedetomidine sedation, but our patient desired maximal amnesia and hypnosis and had no evidence of respiratory dysfunction. As a backup plan, preparations were made for conversion to a non- $\mathrm{MH}$ triggering general anesthesia with induction with fentanyl and ketamine, neuromuscular blockade with rocuronium, maintenance with dexmedetomidine and ketamine infusions with bolus dosing of midazolam and fentanyl, and monitoring of anesthetic depth with a BIS monitor. We planned to avoid nitrous oxide to avoid distension of the abdominal viscera. Thus, we present a case of surgical anesthesia for an open pelvic operation with combined spinal epidural as well as sedation with midazolam, ketamine, and fentanyl that was well tolerated in a patient with possible MM and $\mathrm{MH}$. Our case adds an example to the literature of a safe approach to evaluation and management of a complex patient with an uncommon combination of comorbidities with competing management priorities.

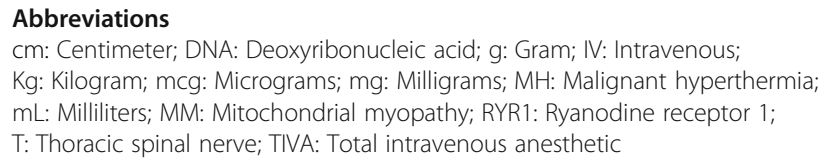

\section{Authors' contributions}

All authors, including MBP, CNO, and MOK participated in the care of the patient, helped draft and revise this manuscript, and read and approved the final manuscript.

\section{Funding}

Not applicable.

\section{Availability of data and materials}

Not applicable.

Ethics approval and consent to participate Not applicable.

\section{Consent for publication}

Written authorization from the patient was provided for submission of a case report.

\section{Competing interests}

The authors declare that they have no competing interests.

Received: 2 August 2019 Accepted: 9 December 2019

Published online: 14 December 2019

\footnotetext{
References

1. Schieren M, Defosse J, Bohmer A, Wappler F, Gerbershagen MU. Anaesthetic management of patients with myopathies. Eur J Anaesthesiol. 2017;34(10): 641-9.

2. Niezgoda J, Morgan PG. Anesthetic considerations in patients with mitochondrial defects. Paediatr Anaesth. 2013;23(9):785-93.

3. Parikh S, Goldstein A, Koenig MK, et al. Diagnosis and management of mitochondrial disease: a consensus statement from the mitochondrial medicine society. Genet Med. 2015;17(9):689-701.
} 
4. Woodward EL, Xiong Z. Use of methohexital and dexmedetomidine for maintenance of anesthesia in a patient with mitochondrial myopathy: a case report. AA Case Rep. 2017;8(2):33-5.

5. Nelson JH, Kaplan RF. Anesthetic management of two pediatric patients with concurrent diagnoses of mitochondrial disease and malignant hyperthermia susceptibility: a case report. AA Case Rep. 2017;9(7):204-6.

\section{Publisher's Note}

Springer Nature remains neutral with regard to jurisdictional claims in published maps and institutional affiliations.

Ready to submit your research? Choose BMC and benefit from:

- fast, convenient online submission

- thorough peer review by experienced researchers in your field

- rapid publication on acceptance

- support for research data, including large and complex data types

- gold Open Access which fosters wider collaboration and increased citations

- maximum visibility for your research: over $100 \mathrm{M}$ website views per year

At $B M C$, research is always in progress.

Learn more biomedcentral.com/submissions 